\title{
THE DEVELOPMENT OF A PHAGE-TYPING SYSTEM FOR GROUP-B STREPTOCOCCI
}

\author{
JACQUELINE STRINGER \\ Division of Hospital Infection, Central Public Health Laboratory, \\ Colindale Avenue, London NW9 5 HT
}

Plate V

GrouP-B streptococci were recognised first as animal pathogens (Stableforth, 1932; Lancefield, 1934). However, Colebrook and Purdie (1937) related group-B streptococci to human disease, and there have since been reports linking group-B streptococci with human infections including septic abortion, puerperal sepsis, bacteraemia, neonatal sepsis, mastitis, meningitis, arthritis, osteomyelitis and inflammation of the urogenital tract (Duma et al., 1969, Eickhoff et al., 1964; Jelinkova, Neubauer and Duben, 1970; Bayer et al., 1976); the most fully documented of these are neonatal sepsis and meningitis. The first published account of neonatal meningitis caused by this organism in Great Britain was given by Jones and Howells (1968). Since then reports from all over the world have implicated group-B streptococci as neonatal pathogens (Jelinkova, 1977). It has been suggested that the newborn acquire the organism during passage through the birth canal (Hood, Janney and Dameron, 1961; Eickhoff et al., 1964; Baker and Barrett, 1973; Franciosi, Knostman and Zimmerman, 1973; Finch, French and Phillips, 1976). Group-B streptococcal infections in neonates appear to be of two types: one, an "early-onset" disease in the first week of life which may be septicaemic or meningitic, the other a "late-onset" disease which is almost always meningitic. There is little doubt that early-onset infections are the result of maternal carriage of the organism, but the source of the infecting streptococcus in late-onset disease is still unknown (Paredes et al., 1977).

The group-B streptococcus is of increasing interest to medical microbiologists as a consequence of the recognition of its role as a human pathogen. It has become of less interest to veterinarians since the availability of penicillin for the treatment of bovine mastitis. The possibility of transmission of group-B streptococci from animal to man cannot be excluded, although serological evidence suggests that the two populations of streptococci are distinguishable (Pattison, Matthews and Maxted, 1955).

In 1922 Ayers and Rupp distinguished the mastitis streptococci from the major human pathogens among the haemolytic streptococci by the ability of the former to hydrolyse sodium hippurate. Avery (1929) noted that bovine strains were tolerant to a concentration of methylene blue in skimmed milk that inhibited those of human origin, and that the bovine strains produced a greater final acidity in glucose broth. Hare and Colebrook (1934) concluded on the basis of biochemical reactions that the saprophytic strains found in man were the same as those that caused bovine mastitis. There were however attempts to show differences between human 
and bovine strains. Brown (1939) showed that there were three fermentative groups based on the utilisation of lactose and salicin, and Butter and de Moor (1967) attempted to distinguish human and animal strains by their origin, haemolysis, acidification of salicin and lactose, and sensitivity to bacitracin.

In addition to establishing the grouping method that bears her name, Lancefield showed that the streptococci of group B could be divided into four types, Ia, Ib, II and III, by the presence of type-specific polysaccharide antigens (Lancefield, 1934). Stableforth (1932) also examined streptococci of bovine origin and later found that his group I corresponded with Lancefield's group B. Using absorbed sera, he developed a typing method based on slide agglutination and recognised 16 types, but these were later examined by Pattison, Matthews and Maxted (1955) and found to be encompassed by the four Lancefield types. The latter workers suggested that many of the Stableforth types were based on protein antigens because treatment with trypsin or pepsin rendered several of the Stableforth type strains indistinguishable. Pattison, Matthews and Howell (1955) also isolated strains of bovine origin that lacked recognised polysaccharide type antigens, but possessed protein antigens which could be extracted with hot acid and detected in precipitin tests. These antigens were designated $R$ and $X$. Recently another type has been described, designated Ic and possessing antigens in common with types $\mathrm{Ia}$ and $\mathrm{Ib}$, but no antigen specific for "type Ic" has been found (Wilkinson and Eagon, 1971).

The existing serological typing system therefore comprises five major types: Ia, Ib, Ic, II, III and two protein antigen types, $\mathrm{R}$ and X. Although different combinations of protein and polysaccharide type antigens may be recognised, the present system is insufficiently discriminating for most epidemiological investigations and it has therefore become necessary to find some additional means of subdividing group-B streptococci.

Phage typing has proved useful in identifying other organisms important in hospital-acquired infections, for example staphylococci and gram-negative bacteria (Williams and Rippon, 1952; Bergan, 1972; Slopek et al., 1976) but little use has been made of streptococcal bacteriophages for typing. There are, however, two reports of the isolation of phages from group-B streptococci (Russell, Norcross and Kahn, 1969; Mtare, Kinsley and Hougland, 1977) but no investigation into the host range of these phages was apparently made. The present report describes the isolation of phages from mitomycin C-treated cultures of group-B streptococci and the application of these phages, in combination with serological typing, for the subdivision of a collection of strains including those apparently showing spread within hospitals.

\section{Materials AND Methods}

Strains examined. Strains of group-B streptococci from human sources were selected from culture collections and routine isolates sent to the Streptococcus Reference Laboratory for serotyping; strains of animal origin were sent by the Central Veterinary Laboratories, Weybridge, Surrey and by Dr R. H. Haug of the Norwegian Defence Microbiological Laboratory. Cultures were stored at room temperature on blood-agar slopes, in glycerol-blood broths at $-18^{\circ} \mathrm{C}$, or in the lyophilised state for long-term storage.

Serological identification of the streptococci was confirmed by precipitation in double-gel diffusion slides (Ouchterlony, 1949) with group- and type-specific rabbit antisera prepared in the Streptococcus Reference Laboratory. Antisera against types Ia (strain 090R), Ib (H36B), Ic (A909), II (18RS21), III (M216), R (Pattison/Compton), and X (Pattison/Compton) were used; the strains indicated in parentheses were used in the production of the typing sera.

Culture media. For primary identification, cultures were grown on horse-blood-agar plates and the deposit from one $50-\mathrm{ml}$ bottle of Todd-Hewitt broth was extracted with $0.2 \mathrm{~N}$, hydro- 
chloric acid for $2 \mathrm{~h}$ at $50^{\circ} \mathrm{C}$ for serological typing (Pattison, Matthews and Maxted, 1955). The medium used for the detection and propagation of bacteriophages was composed of Todd-Hewitt Broth Base (Oxoid) $30 \mathrm{~g}$, Yeast Extract (Oxoid) $2 \mathrm{~g}$, calcium chloride (dried) (BDH Chemicals) $0.012 \mathrm{~g}$ and L-tryptophan (BDH Chemicals) $0.01 \mathrm{~g}$ added to 1 litre of distilled water.The $p \mathrm{H}$ was adjusted to 7.6 and the medium was autoclaved at $115^{\circ} \mathrm{C}$ for $10 \mathrm{~min}$. (Dr H. Russell, personal communication). Solid medium for isolation and typing with bacteriophages was made by the addition of agar (Oxoid No. 1) $0.7 \%(\mathrm{w} / \mathrm{v})$ to this broth, and plates poured from this medium were dried at $37^{\circ} \mathrm{C}$ for $60 \mathrm{~min}$. before use.

Induction and isolation of group-B streptococcal bacteriophages. Cultures of bacteria were grown in $5 \mathrm{ml}$ of the modified Todd-Hewitt broth at $37^{\circ} \mathrm{C}$ for approximately $2 \mathrm{~h}$ or until an optical density of $0 \cdot 2-0 \cdot 4$ at $600 \mathrm{~nm}$ was reached (SP 600 Pye Unicam spectrophometer). The suspensions were then used to flood agar plates. The remainder of the suspensions was then centrifuged at 3000 r.p.m. for $15 \mathrm{~min}$. and the supernates were filtered through HA $0.45-\mu \mathrm{m}$ membrane filters (Millipore Ltd, Wembley, Middlesex). These supernatants were then crossspotted on the seeded lawns which had been dried at $37^{\circ} \mathrm{C}$ for $30 \mathrm{~min}$.; this was done with the aid of a multiloop applicator (Lidwell, 1959; Biddulph and Co., Manchester).

Lysogenic bacteriophages were induced with mitomycin $\mathrm{C}$ by incubation of cultures at $37^{\circ} \mathrm{C}$ for $2 \mathrm{~h}$ and then addition of mitomycin $\mathrm{C}$ (Sigma Chemical Co., St Louis, USA) to each culture to a final concentration of $0 \cdot 1 \mu \mathrm{g} / \mathrm{ml}$ (Otsuji et al., 1959). The cultures were then incubated for a further $2 \mathrm{~h}$, centrifuged at 3000 r.p.m. for $15 \mathrm{~min}$. and cross-spotted on streptococcal lawns with the Lidwell applicator.

All plates were incubated aerobically for $18 \mathrm{~h}$ at $30^{\circ} \mathrm{C}$ and phage activity was indicated by plaques in the lawns after incubation.

Propagation of bacteriophages. For the initial propagation of any phage, a single plaque was picked and inoculated into $5 \mathrm{ml}$ of modified Todd-Hewitt broth with a few colonies of the propagating strain. The broth was incubated for approximately $4 \mathrm{~h}$, then harvested as described. The supernate was titrated in tenfold dilutions on lawns of the propagating strain. This procedure was repeated twice to ensure purity of the phage.

Bulk phage suspensions were prepared by inoculation of a phage and culture suspension, in a ratio of 10 phage particles to 1 bacterial chain, into $15 \mathrm{ml}$ of modified Todd-Hewitt broth. The broth was incubated at $30^{\circ} \mathrm{C}$ for $4 \mathrm{~h}$ or until lysis could be seen to have taken place. It was then centrifuged at 3000 r.p.m. for $15 \mathrm{~min}$. and the supernate was titrated in tenfold dilutions in the modified Todd-Hewitt broth and spotted on a lawn of the propagating strain from sterile $0.02-\mathrm{ml}$ dropping pipettes. The propagating strain for any phage was the strain on which the phage was initially detected and later used for its propagation. The plates were incubated for $18 \mathrm{~h}$ at $30^{\circ} \mathrm{C}$ and the titre of the phage suspension defined as the dilution that produced just less than confluent lysis. Results from this dilution on routine strains were recorded thus: no visible evidence of specific lysis, $-; 1-20$ plaques, $\pm ; 21-50$ plaques, $+; 51$ plaques-semi-confluent lysis, ++ . The number of phage particles per $\mathrm{ml}$ was also calculated for each phage, if this exceeded $10^{7}$ plaque-forming units per $\mathrm{ml}$ (p.f.u./ml) the phage suspension was considered acceptable and was filtered through a membrane filter.

Lytic spectrum. To ensure that phage stocks remained pure at each propagation and to monitor any possible genetic changes, that might affect the host range of a phage, the basic characteristics used to classify them were plaque size and appearance, and the lytic spectrum, which is the characteristic pattern of lysis produced by the phage on a selected set of 21 bacterial strains. The method used was that devised for Staphylococcus aureus phages by Rippon (1956). Phage filtrates under examination were first tested undiluted for their ability to lyse any of the 21 test strains. If the filtrate consequently had a titre greater than $10^{4}$ it was diluted to the level at which semi-confluent lysis was produced at a dilution of 1 in $10^{4}$. This was necessary to eliminate any "inhibitory effect" which was sometimes produced by phage suspensions with titres greater than $10^{4}$. The phage filtrate was then titrated by spotting a series of tenfold dilutions on those test strains that were lysed by the undiluted suspension. The titre on each strain lysed, relative to that on the homologous propagating strain, was then calculated. The lytic spectrum of each newly propagated phage was compared with that of the standard stock phage suspension. 
Provided that the two phage suspensions showed similar lytic activity the newly propagated phage was considered acceptable. Variation between grades 4 and 5, between 3 and 4, and the loss or gain of grade-1 and grade-2 reactions were allowed (Blair and Williams 1961; Stringer, (unpublished).

Determination of routine test dilutions of typing phages. Phages were propagated until a titre of $10^{4}$ was obtained; this corresponded approximately to $10^{7}$ p.f.u. $/ \mathrm{ml}$. The phages were then tested undiluted and in tenfold dilutions to 1 in $10^{4}$ on a wide selection of routine isolates. The highest dilution for each phage that produced the widest spectrum of lysis without producing inhibitory reactions was chosen as the routine phage-typing test dilution (RTD). This dilution was not the same for all the phages.

In most other phage-typing systems, for example those used for klebsiellae, pseudomonads or staphylococci, the RTD is the dilution of phage producing just less than confluent lysis on its propagating strain. Phages for group-B streptococci used at this dilution were very restricted in their spectrum of lysis. The predetermined RTDs of the group-B phages were approximately 100 times the dilution producing semiconfluent lysis (table I).

The phage-typing set. Initially 31 phages were used but this is a large number of phages to maintain and propagate; moreover, two plates were required for each strain tested because only 25 phages could be applied to each 90 -mm agar plate. Twenty-five or fewer phages conveniently make up a basic set. The effect on the discriminatory power of the system of eliminating various phages from the set was assessed in tests on 216 epidemiologically unrelated isolates. These strains were obtained from patients with urinary-tract or systemic infections, either blood or cerebrospinal fluid (CSF) cultures, or from superficial sites on patients attending an antenatal clinic, a maternity hospital or a clinic for sexually transmitted diseases (STD). They were collected during a period of 6 months, and only one isolate from any one person was included. All the strains were serotyped with antisera against types Ia, Ib, Ic, II, III, R and X, and phage typed with the full set of 31 phages. A strain was considered to be typable if it was lysed strongly, i.e., gave a ++ reaction, by one or more phages.

\section{RESULTS}

\section{The phage typing set}

The original 31 phages are characterised in table I by their carrier strain, propagating strain and plaque morphology. Most phages gave small plaques and the lysis by all but two of the phages was clear. In general the plaques had a punched-out appearance.

There were similarities between phages 8,9 and 10 , and between 20,21 and 22. In each of these groups the phages shared the same propagating strain, and the close association of the phages within them was also shown by the fact that they usually lysed the same routine strains. Table I also lists the concentrations of the phages at their routine test dilutions. If strong phage-reaction differences were not allowed between strains, 88 distinct lytic patterns could be recognised among the 216 epidemiologically independent isolates examined. In an attempt to reduce the number of phages in the basic typing set, the results from phages that appeared to be very similar to another in the set (phages 9 and 10,21 and 22) or were so restricted in host range that they lysed few routine strains (phages 6, 23, 25) were eliminated; when these results were omitted, 77 distinct phage lytic patterns remained. This reduction in the number of phage patterns was not great, and because the serological typing further subdivided the strains, the small reduction in the discriminatory power 


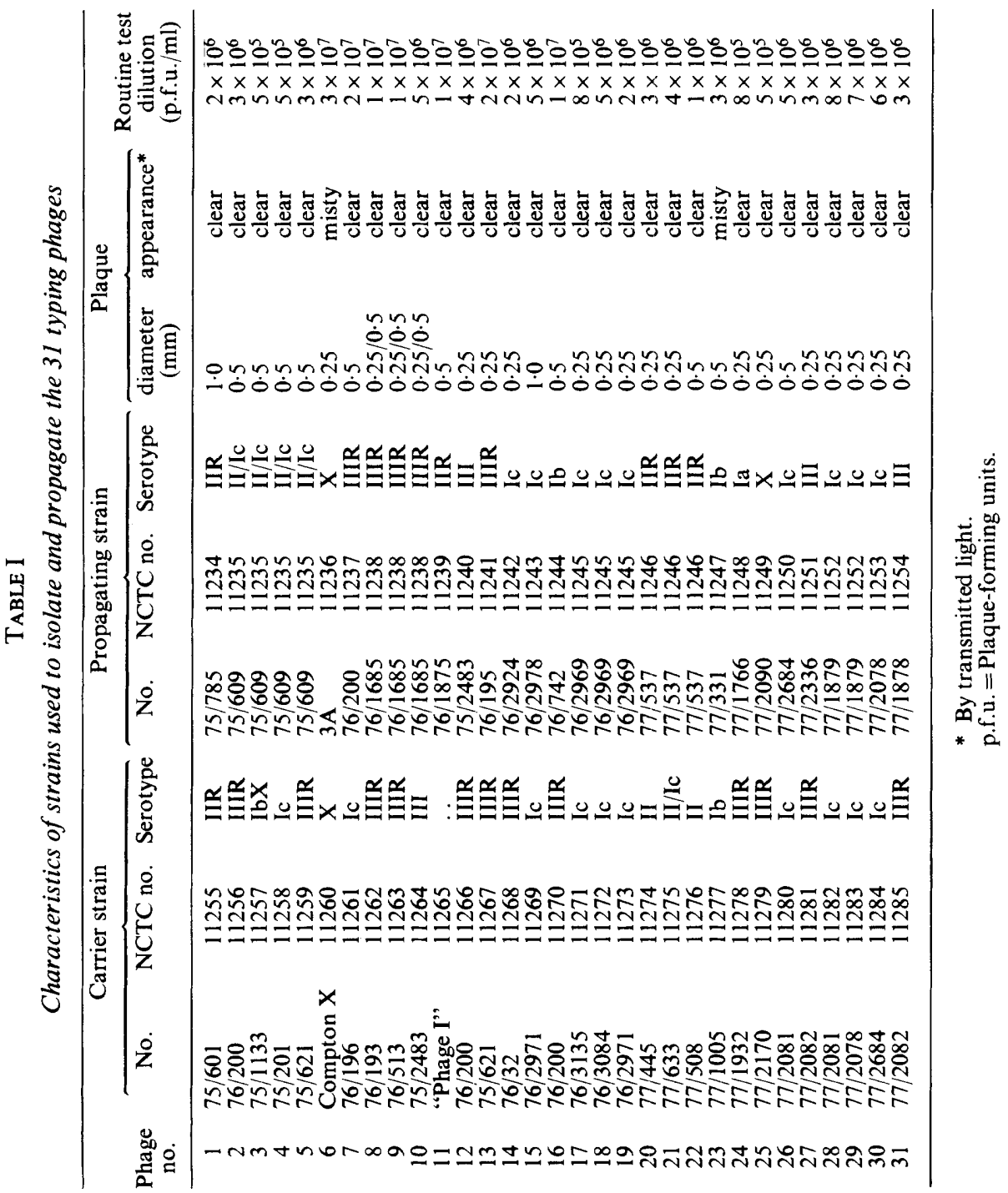


TABLE II

Serotype distribution of 216 epidemiologically unrelated strains of group-B streptococci and percentage typable with 24 phages

\begin{tabular}{l|cc}
\hline Serotype & $\begin{array}{c}\text { Number of } \\
\text { strains }\end{array}$ & $\begin{array}{c}\text { Percentage phage } \\
\text { typable }\end{array}$ \\
\hline Ia & 16 & 81 \\
Ib & 26 & 81 \\
Ic & 42 & 88 \\
II & 43 & 80 \\
III & 60 & 83 \\
Protein only & 29 & 78 \\
N.T. & 216 & 82 \\
All & & \\
\hline
\end{tabular}

of the system was compensated by the reduction of work involved. Table II shows the serotype distribution of the 216 isolates and the percentage of each that were typable by one or more phages; in all, $82 \%$ of the isolates were typable.

\section{Host range of bacteriophages}

Strains sent to the Streptococcus Reference Laboratory for serological identification were phage typed with the set of 24 phages. For strains received from August 1977 until December 1978, an analysis of the serological and phage-typing results has been made in relation to their geographical origin and host.

British strains of human origin were obtained from a variety of sources; many were from superficial sites on newborn babies or the female genital tract. Some of the strains were from cultures of urine, blood and spinal fluid (CSF). Strains from Nigeria were largely from superficial sites on patients attending STD clinics, and the remainder were from well or sick babies and their mothers. The small collection of strains from America were from superficial sites on mothers and babies and from blood and CSF cultures of sick neonates. The bovine strains were all from cows with mastitis.

TABLE III

Serotype distribution and phage-typability of strains examined August 1977-December 1978

\begin{tabular}{|c|c|c|c|c|c|c|c|c|c|}
\hline \multirow[b]{2}{*}{ Source } & \multicolumn{7}{|c|}{ Number (percentage) of strains in serotype } & \multirow[b]{2}{*}{ Total } & \multirow{2}{*}{$\begin{array}{c}\text { Percentage } \\
\text { of strains } \\
\text { typable } \\
\text { by phage }\end{array}$} \\
\hline & Ia & Ib & Ic & II & III & $\mathbf{R}, \mathrm{X}, \mathrm{Ic}$ protein & NT & & \\
\hline \multirow{2}{*}{$\begin{array}{c}\text { Human } \\
\text { Britain }\end{array}$} & & & & & & & & & \\
\hline & $\begin{array}{c}80 \\
(8 \cdot 7)\end{array}$ & $\begin{array}{c}96 \\
(10 \cdot 4)\end{array}$ & $\begin{array}{c}183 \\
(19 \cdot 9)\end{array}$ & $\begin{array}{c}171 \\
(18 \cdot 6)\end{array}$ & $\begin{array}{c}236 \\
(25 \cdot 7)\end{array}$ & $\begin{array}{c}120 \\
(13 \cdot 1)\end{array}$ & $\begin{array}{c}33 \\
(3 \cdot 6)\end{array}$ & 919 & 80 \\
\hline Nigeria & $\begin{array}{c}0 \\
(0)\end{array}$ & $\begin{array}{c}7 \\
(4 \cdot 8)\end{array}$ & $\begin{array}{c}10 \\
(6 \cdot 9)\end{array}$ & $\begin{array}{c}6 \\
(4 \cdot 1)\end{array}$ & $\begin{array}{c}76 \\
(52 \cdot 4)\end{array}$ & $\begin{array}{c}40 \\
(27 \cdot 6)\end{array}$ & $\begin{array}{c}6 \\
(4 \cdot 1)\end{array}$ & 145 & 50 \\
\hline $\begin{array}{r}\text { USA } \\
\text { Bovine }\end{array}$ & $\begin{array}{c}1 \\
0 \\
(0)\end{array}$ & $\begin{array}{c}4 \\
6 \\
(4 \cdot 5)\end{array}$ & $\begin{array}{c}4 \\
9 \\
(6 \cdot 7)\end{array}$ & $\begin{array}{c}7 \\
8 \\
(6 \cdot 0)\end{array}$ & $\begin{array}{c}5 \\
14 \\
(10 \cdot 4)\end{array}$ & $\begin{array}{c}0 \\
57 \\
(42 \cdot 5)\end{array}$ & $\begin{array}{c}1 \\
40 \\
(29 \cdot 9)\end{array}$ & $\begin{array}{c}22 \\
134\end{array}$ & $\begin{array}{l}82 \\
77\end{array}$ \\
\hline
\end{tabular}

$\mathrm{NT}=$ Not typable by precipitin test with the set of seven sera. 
The serotype distribution and phage typability of these strains are summarised in table III. The serotype distribution of the bovine strains is clearly different from that of the British human strains because only a small percentage of bovine strains possessed any recognisable polysaccharide antigen but the proportion of strains found to be phage typable was comparable to that of human strains isolated in Britain. Many of the phage lytic patterns seen among bovine strains were also observed among the human strains, suggesting that the two populations of streptococci may not be completely distinct from each other. Some phage lytic patterns were more common than others, but none appeared to be serotype specific. Two of the more common patterns are illustrated in the figure; these patterns occurred within all the serotypes but a reaction with phage 11 was common in strains of serotype II and the second pattern was often seen with strains of serotype Ic.

In addition to phage lysis, several other phenomena were observed with some strains. Secondary growth frequently occurred over zones of confluent lysis, and within this growth secondary lysis could occasionally be seen, usually visible as individual plaques; this phenomenon is being further investigated. Inhibition reactions also occurred and could be recognised as zones of reduced growth, frequently resembling confluent phage lysis. The phenomenon, which was frequently associated with high-titre preparations, could be recognised by diluting the phage suspension, when the effect was lost and no individual plaques developed. This form of lysis was described in detail by Williams and Rippon (1952) who frequently encountered it with $S$. aureus. Inhibition reactions were scored as 0 .

In contrast, the strains from Nigeria were not readily lysed by the phages, only $50 \%$ of them being typable; the serotype distribution was also different from that of the British strains, with more than $50 \%$ in serotype III. Of the 22 American strains, 18 were phage typable and the patterns produced were similar to those of the British strains.

\section{Reproducibility and discrimination of serological and phage-typing methods}

The set of 24 phages typed more than $75 \%$ of clinical isolates. Because the

TABLE IV

Differences in phage-typing patterns among epidemiologically related sets of group-B streptococci

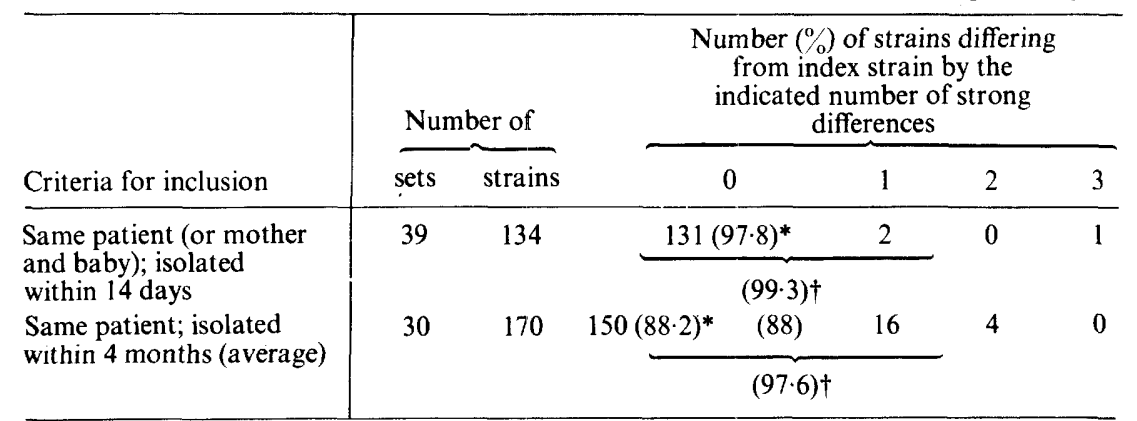

* Percentage of 'correct' results if no strong differences are permitted.

$\dagger$ Percentage of 'correct' results if one strong difference is permitted. 
phage lytic patterns were not serotype specific, a two-stage typing system was used, in which phage typing subdivided serotypes.

The reproducibility of the serological and phage-typing systems was evaluated by typing epidemiologically related sets of isolates. "Short-term" isolates were obtained from pregnant women and their babies after delivery, in whom cultures were taken from several sites during a period of 14 days. "Longterm" isolates were obtained from pregnant women who were swabbed at three sites in the genital tract on several occasions during pregnancy, usually at 16 , 28,36 weeks, and postnatally. The results of serotyping and phage typing these strains are summarised in tables IV and V. The differences in phagetyping patterns (table $\mathrm{V}$ ) may indicate the degree of inherent variability of the method. However, if a difference of one strong reaction is permitted between epidemiologically related strains, less than $3 \%$ of the comparisons would have indicated incorrectly that the strains were distinguishable. The same collection of strains was used to investigate the reproducibility of serotyping. Among the short-term isolates only one of these differences was major-the apparent absence of a Ia polysaccharide antigen. The other nine were instances of the apparent loss or gain of an R-protein antigen. Among the long-term isolates there were nine major differences, and the other serological discrepancies were either the loss or gain of a protein antigen. All members of sets in which serological discrepancies were found had identical phage-typing patterns. It was clear that variation between apparently related strains increased with an increase in the lapse of time between isolation and typing of the streptococci, but it was considered that a difference of more than one strong phage reaction constituted reliable grounds for discrimination between strains in most circumstances.

The discriminatory power of the two-stage typing system was next investigated by examining 206 epidemiologically unrelated strains from one hospital isolated during a 6 -month period. They were from superficial sites on patients

TABLE V

Differences in serotyping results among epidemiologically related sets of group-B streptococci

\begin{tabular}{|c|c|c|c|c|}
\hline \multirow[b]{2}{*}{ Criteria for inclusion } & \multirow[b]{2}{*}{ Serotype } & \multicolumn{2}{|c|}{ Number of } & \multirow{2}{*}{$\begin{array}{c}\text { Number } \\
\text { of strains } \\
\text { (sets) } \\
\text { discrepan }\end{array}$} \\
\hline & & sets & strains & \\
\hline $\begin{array}{l}\text { Same patient (or mother } \\
\text { and baby); isolated } \\
\text { within } 14 \text { days }\end{array}$ & $\begin{array}{l}\text { Any } \\
\text { Polysaccharide } \\
\text { Protein Ic } \\
\text { R } \\
\text { X }\end{array}$ & $\begin{array}{r}39 \\
35 \\
8 \\
19 \\
2\end{array}$ & $\begin{array}{r}134 \\
119 \\
38 \\
59 \\
6\end{array}$ & $\begin{array}{l}10(4) \\
1(1)^{*} \\
0(0) \\
9(3) \\
0(0)\end{array}$ \\
\hline $\begin{array}{l}\text { Same patient; isolated } \\
\text { within } 4 \text { months (average) }\end{array}$ & $\begin{array}{l}\text { Any } \\
\text { Polysaccharide } \\
\text { Protein Ic } \\
\text { R } \\
\text { X }\end{array}$ & $\begin{array}{r}30 \\
25 \\
8 \\
9 \\
0\end{array}$ & $\begin{array}{r}170 \\
136 \\
43 \\
56 \\
0\end{array}$ & $\begin{array}{l}18(6) \\
9(3) \dagger \\
2(1) \\
7(2) \\
0(0)\end{array}$ \\
\hline
\end{tabular}

\footnotetext{
* Apparent loss of Ia polysaccharide antigen.

$\dagger$ Loss of III polysaccharide antigen in one set; gain of II polysaccharide antigen in one set; loss of Ib polysaccharide antigen in one set.
} 


\section{Phage tyPing of GROUP-B STREPTOCOCCI}
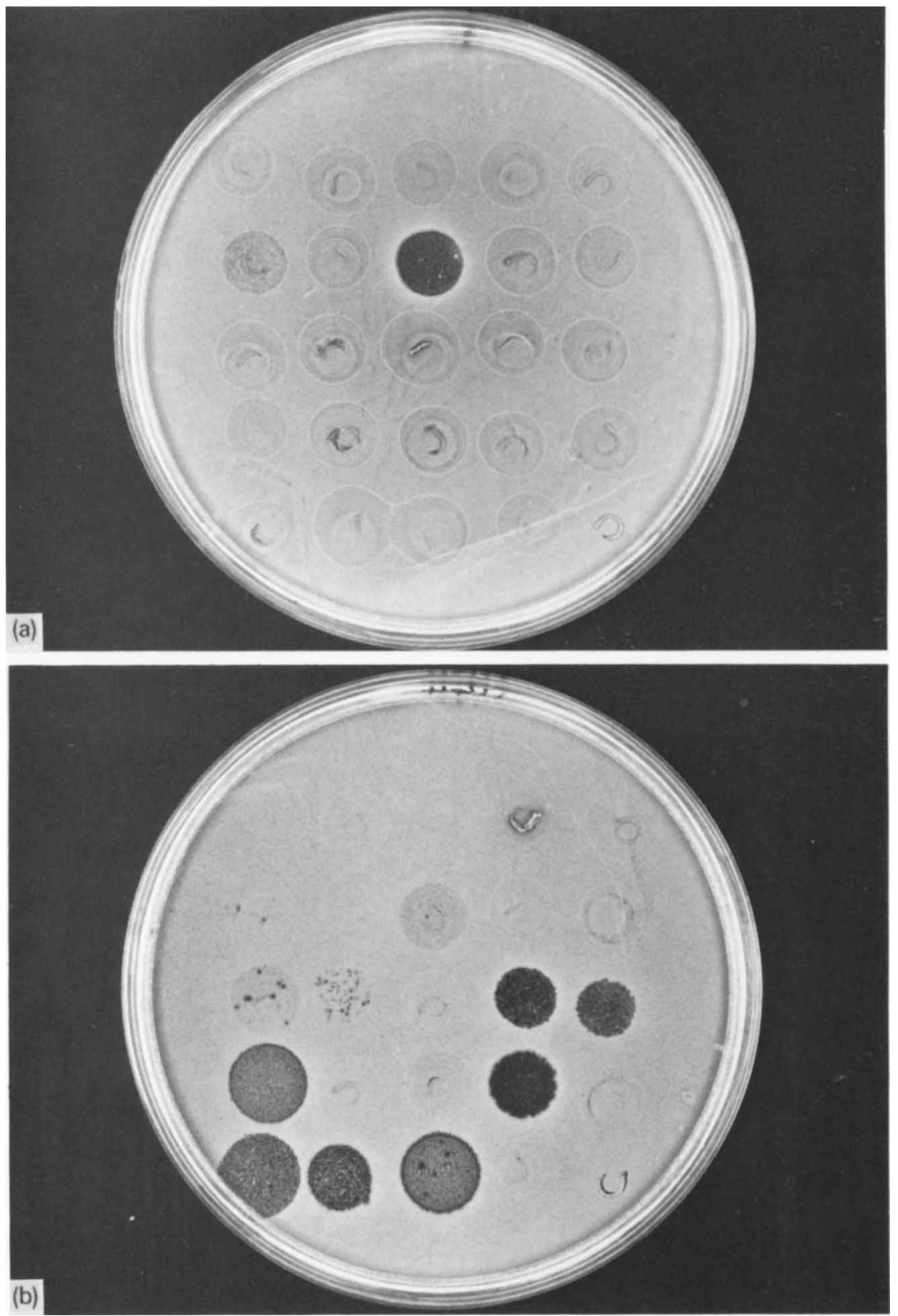

FIGURE.-Plan of phages in typing block:

$\begin{array}{rrrrr}1 & 2 & 3 & 4 & 5 \\ 7 & 8 & 11 & 12 & 13 \\ 14 & 15 & 16 & 17 & 18 \\ 19 & 20 & 24 & 26 & 27 \\ 28 & 29 & 30 & 31 & \end{array}$

(a) Phage pattern $7^{++}, 11^{+++}$. (b) Phage pattern (11), $\left(14^{ \pm}\right), 15^{+}, 17^{+++}, 18^{+++}, 19^{+++}, 26^{++}$, $28^{+++}, 29^{+++}, 30^{+++}$; resistant overgrowth on lysis by phages $19,28,29$ and 30 ; secondary lysis in the overgrowth of phage 30 . 
TABLE VI

Discrimination among epidemiologically unrelated strains of group B streptococci from one hospital

\begin{tabular}{|c|c|c|c|c|c|c|}
\hline \multirow[b]{3}{*}{ Serotype } & \multicolumn{3}{|c|}{ Number $(\%)$ of } & \multirow{2}{*}{\multicolumn{3}{|c|}{$\begin{array}{l}\text { Percentage frequency } \\
\text { of the indicated } \\
\text { more common } \\
\text { sero-phage "types" }\end{array}$}} \\
\hline & \multirow{2}{*}{$\begin{array}{l}\text { strains } \\
\text { examined }\end{array}$} & \multirow{2}{*}{$\begin{array}{l}\text { strains } \\
\text { untypable } \\
\text { by phage }\end{array}$} & \multirow{2}{*}{$\begin{array}{c}\text { distinct } \\
\text { phage } \\
\text { patterns* }\end{array}$} & & & \\
\hline & & & & 1 & 2 & 3 \\
\hline Ia & $8 \quad(3.9)$ & $1(0 \cdot 5)$ & 5 & $1 \cdot 0$ & & \\
\hline Ib & $37(18 \cdot 0)$ & $5(2.4)$ & 18 & $2 \cdot 4$ & $2 \cdot 4$ & 1.5 \\
\hline Ic & $55(26 \cdot 7)$ & $11(5 \cdot 3)$ & 21 & $3 \cdot 4$ & $3 \cdot 4$ & 2.9 \\
\hline II & $42(20 \cdot 4)$ & $7(3 \cdot 4)$ & 20 & 3.9 & 1.9 & 1.0 \\
\hline & $42(20 \cdot 4)$ & $8(3.9)$ & 17 & $6 \cdot 3$ & $1 \cdot 5$ & 1.0 \\
\hline X only & $7(3.4)$ & $4(1.9)$ & 3 & $\cdots$ & $\cdots$ & $\ldots$ \\
\hline $\mathbf{R}+\mathbf{N T}$ & $15(7 \cdot 3)$ & $5(2 \cdot 4)$ & 10 & $\ldots$ & $\ldots$ & $\cdots$ \\
\hline Total & 206 & 41 & 94 & & & \\
\hline
\end{tabular}

* Difference established by $>1$ strong phage reaction

attending an STD clinic or the maternity department, or from samples of urine. Only one isolate from each patient was included. Serologically, seven different groups of strains could be recognised (table VI) and three of these each comprised more than $20 \%$ of the total. The number of distinct phage-typing patterns in each serogroup was then determined, and for this purpose a pattern was considered to be distinct when it differed from all others in the serogroup by more than one strong phage reaction. In all, 94 different sero-phage "types" could be recognised. The more common sero-phage "types" are represented as a percentage of the total number of strains examined; the largest single "type" comprised $6.3 \%$ of the total; few others exceeded $3 \%$. Thus the probability that two isolates would belong to the same sero-phage "type" by chance would seldom exceed 0.02 .

\section{Discussion}

In this investigation we attempted to subdivide the serological types of group-B streptococci by phage typing. This enabled us to investigate more precisely the involvement of the organism in neonatal sepsis. More than $75 \%$ of clinical isolates from Great Britain and the United States were phage typable. Considerably less success was achieved with strains from Nigeria. It is of interest that Skjold and Wannamaker (1976), working with phages isolated from group-A type-49 streptococci, suggested that there may have been geographical specificity of the phages they isolated; a similar specificity may exist among the phages of group-B streptococci. The phages studied so far were all from streptococci isolated in Britain but they appear to type bovine and human strains from Norway, Germany and Holland (results not presented here), and the United States with comparable frequency. This suggests that the group-B streptococci in Nigeria are significantly different from those in other countries. 
Approximately $75 \%$ of the bovine strains from Britain, Germany and Norway were phage typable and many of the lytic patterns of these strains were also seen in the human strains. This may support the view that the two streptococcal populations are not completely distinct.

Some phage patterns were encountered more often than others. Although no one pattern appeared to be specific for any one serotype, there appeared to be a partial serotype association with some phages. For example, phage 12 was frequently associated with serotype III, phage 11 with serotype II, and phage 14 with serotype Ic, but these phage reactions were not exclusively found in these serotypes. The significance of these phage-serotype associations is uncertain and is being investigated.

The shortened set of 24 phages provided an easy-to-handle typing system that was reproducible and, when used in conjunction with serotyping, highly discriminatory. It has been used to great advantage in tracing the spread of group-B streptococci in several hospitals (Stringer and Maxted 1979; Parker 1979). With a prevalence of serious neonatal infection caused by group-B streptococci reported variously from 1.1 to 6 per 1000 live births (Finch, French and Phillips 1976; Pass et al., 1979), the study of the spread of this organism is of clinical importance.

\section{SUMMARY}

A typing system for group-B streptococci, based on the use of 24 phages, has been evaluated. Used in conjunction with serotyping, it gave highly discriminating and reproducible results.

\section{REFERENCES}

AVERY, R. C. 1929. Differentiation of hemolytic streptococci of human and of dairy origin by methylene blue tolerance and final acidity. J. exp. Med., 50, 463.

Ayers, S. H. AND RUPP, P. 1922. Differentiation of hemolytic streptococci from human and bovine sources by the hydrolysis of sodium hippurate. J. infect. Dis., 30, 388.

BAKER, C. J. AND BARRETT, F. F. 1973. Transmission of group B streptococci among parturient women and their neonates. J. Pediat., 83, 919.

Bayer, A. S., Chow, A. W., Anthony, B. F. And Guze, L. B. 1976. Serious infections in adults due to group B streptococci-clinical and serotypic characterization. Am.J. Med., 61, 498.

Bergan, T. 1972. A new bacteriophage typing set for Pseudomonas aeruginosa 2. Characterization and comparisons of new and previous typing sets. Acta. path. microbiol. scand., 80B, 189.

Blair, J. E. And Williams, R. E. O. 1961. Phage typing of staphylococci. Bull. Wld. Hlth Org., $24,771$.

BRown, J. H. 1939. Double-zone beta-hemolytic streptococci: their cultural characteristics, serological grouping, occurrence, and pathogenic significance. J. Bact., 37. 133.

ButTER, M. N. W. AND DE MOOR, C. E. 1967. Streptococcus agalactiae as a cause of meningitis in the newborn, and of bacteraemia in adults. Differentiation of human and animal varieties. Antonie van Leeuwenhoek, 33, 439.

Colebrook, L. AND Purdie, A. W. 1937. Treatment of 106 cases of puerperal fever by sulphanilamide (streptocide). Lancet, 2, 1237. 
Duma, R. J., Weinberg, A. N., Medrek, T. F. And Kunz, L. J. 1969. Streptococcal infections. A bacteriologic and clinical study of streptococcal bacteremia. Medicine, Baltimore, 48, 87.

Eickhoff, T. C., Klein, J. O., Daly, A. K., Ingall, D. and Finland, M. (1964. Neonatal sepsis and other infections due to group B beta-hemolytic streptococci. New Eng. J. Med., 271, 1221.

Finch, R. G., French, G. L. And Phillips, I. 1976. Group B streptococci in the female genital tract. Br. med. J., 1, 1245.

Franciosi, R. A., Knostman, J. D. and Zimmerman, R. A. 1973. Group B streptococcal neonatal and infant infections. J. Pediat., 82, 707.

HaRe, R. AND COLEBROOK, L. 1934. The biochemical reactions of haemolytic streptococci from the vagina of febrile and afebrile parturient women. J. Path. Bact., 39, 429.

Hood, M., Janney, A. and Dameron, G. 1961. Beta hemolytic streptococcus group B associated with problems of the perinatal period. Amer. J. Obstet. Gynec., 82, 809.

Jelinkova, J. 1977. Group B streptococci in the human population. In Current topics in microbiology and immunology, 76, 127.

Jelinkova, J., Neubauer, M. AND Duben, J. 1970. Group B streptococci in human pathology. Zbl. Bakt. ParasitKde 1. Abt. Orig., 214, 450.

JoNES, H. E. AND HowelLs, C. H. L. 1968. Neonatal meningitis due to Streptococcus agalactiae. Postgrad. med. J., 44, 549.

LANCEFIELD, R. C. 1934. Serological differentiation of specific types of bovine hemolytic streptococci (Group B). J. exp. Med., 59, 441.

Lidwell, O. M. 1959. Apparatus for phage-typing of Staphylococcus aureus. Mon. Bull. Minist. Hlth, 18, 49.

Mtare, D. N., Kinsley, R. N. and Hougland, A. E. 1977. Characterization of streptococcus bacteriophage isolated from sewage using Streptococcus agalactiae, Streptococcus bovis, Streptococcus faecalis and Streptococcus faecium. Abstr. ann. Meeting Am. Soc. Microbiol., p. 270.

Otsuji, N., Sekiguchi, M., Iijima, T. And TAKaGi, Y. 1959. Induction of phage formation in the lysogenic Escherichia coli K-12 by mitomycin C. Nature, Lond., 184, 1079.

OuCHTERLONY, O. 1949. Antigen-antibody reactions in gels. Acta. path. microbiol. scand., 26, 507.

Paredes, A., Wong, P., Mason, E. O., Taber, L. H. and Barrett, F. F. 1977. Nosocomial transmission of group B streptococci in a newborn nursery. Pediatrics, 59, 679.

PARKER, M. T. 1979. Infections with group-B streptococci. J. antimicrob. Chemother., 5, (suppl. A) 27.

Pass, M. A., Gray, B. M., Khare, S. and Dillon, H. C. 1979. Epidemiological studies of group-B streptococcal infections in neonates. In Pathogenic streptococci, edited by M. T. Parker. Reedbooks: Chertsey, p. 175.

Pattison, I. H., Matthews, P. R. J. and Howell, D. G. 1955. The type classification of group-B streptococci, with special reference to bovine strains apparently lacking in type polysaccharide. J. Path. Bact., 69, 51.

Pattison, I. H., Matthews, P. R. J. and Maxted, W. R. 1955. Type classification by Lancefield's precipitin method of human and bovine group B streptococci isolated in Britain. J. Path. Bact., 69, 43.

RIPPON, J. E. 1956. The classification of bacteriophages lysing staphylococci. J. Hyg., Camb., $54,213$.

Russell, H., Norcross, N. L. and KahN, D. E. 1969. Isolation and characterization of Streptococcus agalactiae bacteriophage. J. gen. Virol. 5, 315.

SkJold, S. AND Wannamaker, L. W. 1976. Method for phage typing group A type 49 streptococci. J. clin. Micro., 4, 232.

Slopek, S., Przondo-Hessek, A., Milch, H. and Deak, S. 1967. A working scheme for bacteriophage typing of Klebsiella bacilli. Arch. Immunol. Ther. exp., 15, 589.

Stableforth, A. W. 1932. Studies on bovine mastitis. VII. The serological characters of mastitis streptococci. J. comp. Path. Ther., 45, 185. 
Stringer, J. AND Maxted, W. R. 1979. Epidemiological evaluation of a phage-typing system for group-B streptococci. In Pathogenic streptococci, edited by M. T. Parker. Reedbooks: Chertsey, p. 262.

Wilkinson, H. W. and Eagon, R. G. 1971. Type-specific antigens of group B type Ic streptococci. Infect. Immun., 4, 596.

Williams, R. E. O. AND RipPON, J. E. 1952. Bacteriophage typing of Staphylococcus aureus. J. Hyg., Camb., 50, 320. 